\title{
DE FUNCTIE VAN DE BALANS
}

\section{door Prof. G. L. Groeneveld}

I Wanneer collega Van Kampen de pen ter hand neemt, kan men er zeker van zijn, dat er geen ,generally accepted accounting principles" naar voren zullen worden gebracht. Integendeel, Van Kampen kiest zijn eigen baan in de vrije ruimte, in eigen logica voortbouwend naar fris verworven inzicht. De resultaten daarvan zijn veelal tegengesteld aan min of meer algemeen gehuldigde opvattingen.

Van Kampen is een benijdenswaardige figuur, zoals wij in geen enkele wetenschap kunnen ontberen om het denken te stimuleren en elkeen de nodige ,motivasie" te geven zich op zijn eigen denkwereld te bezinnen. Ik kan mij daarom voorstellen, dat de redactie de behoefte heeft gevoeld om iemand, in casu ondergetekende, te vragen enkele critische kanttekeningen bij v.K.'s artikel te plaatsen.

In v.K.'s bijdrage over de functie van de balans in het nummer van april 1969 is het niet anders dan boven is aangegeven. Wel neemt v.K. daarin een aanloop die conformistisch aandoet, n.l. wanneer hij zegt te streven naar een objectieve winstberekening en zich daarbij te willen baseren op het continuiteitsstreven als diepste grondslag voor het handelen van de ondernemingsleiding. Daarmede is de parallelliteit van gedachte voor mij echter reeds ten einde. Kostprijs, financiering en organisatie, zegt v.K., behoren tot de bedrijfseconomie, ontspruiten aan de onderneming zelve, uit haar drang naar continuīteit, maar balansmaken kan de onderneming zonder schade nalaten, dat is een vermogensrechtelijke zaak. Winstuitkering heeft geen directe relatie met de continuiteit, maar is integendeel een inleiding tot de liquidatie van een gedeelte van het ondernemingsvermogen.

Hoe nu! ben ik geneigd nu te zeggen. Voordat van continuiteit sprake kan zijn, zal de onderneming toch eerst moeten worden gesticht, zal er moeten worden ondernomen. Wat kan daarvoor een ander economisch motief zijn dan op die wijze deel te nemen aan het algemene streven naar inkomen ter verhoging van 's mensen welvaart. Dit streven blijft behouden en doet zich bij voortduring gedurende de werkzaamheid van de onderneming met kracht gelden. Elke verwezenlijking van welk doeleinde van de onderneming dan ook is gebonden aan de realisering van het inkomensstreven. Of en in hoeverre men daarin slaagt, moet door de ondernemingsleiding bij voortduring worden nagegaan, vastgesteld, gecontroleerd. En dit zou dan niet, ,uit de onderneming zelve ontspruiten"? Kostprijs zou wèl zo'n aangelegenheid zijn, maar de op basis van die kostprijs gevoerde prijs- en winstpolitiek zou dit niet zijn? Financiering zou wèl zo'n aangelegenheid zijn, maar de verhouding tot de vermogensmarkt, de hoogte van de prijs van het vermogen, de te voeren dividend- en reserveringspolitiek zou daar dan niet toe behoren? Jawel, zegt v.K., maar er is in tweeërlei opzicht verschil tussen kostprijs, financierings- en organisatievraagstukken enerzijds en de jaarrekening anderzijds.

a. Wij hebben bij de jaarrekening te doen met zaken van een meer juridisch 
aspect, de rechten van winstgerechtigden hangen af van getroffen overeenkomsten. (v.K.) Dit laatste is zeker waar, want schier elk verschijnsel in de onderneming hangt af van getroffen overeenkomsten. De uitbetaling van lonen en salarissen, het treffen van sociale voorzieningen, het sluiten van inkoopcontracten, het accepteren van orders, alles geschiedt op basis van contracten. Alleen: wij hebben met dit aspect niet anders te maken dan voor zover het van directe invloed is op bedrijfseconomische begripsvorming, zoals b.v. de onderscheiding tussen vreemd en eigen vermogen. Niet het juridische, maar het bedrijfseconomische aspect is voor ons relevant.

b. Van de gegevens, die de jaarrekening kan verschaffen, moet de ondernemingsleiding reeds lang alles weten. Ze heeft voor haar eigen belangen de jaarrekening in het algemeen niet nodig. (v.K.)

Ja, dat de communicatiestroom naar de leiding méér moet bevatten dan de gegevens van de jaarrekening en dat deze gegevens op korter termijn dan een jaar moeten worden verstrekt is duidelijk.

De boekhouding is ten enenmale primair een informatiesysteem, dat de leiding continueel op de hoogte moet houden a) van het instandhouden van de bedrijfseconomische kringloop van het bedrijf, subsidiair van de - op winstbestemming anticiperende - toeneming van het lopend resultaat; $b$ ) van het resultaat van de maatregelen van de leiding in vergelijking met het daarvan verwachte resultaat, zowel in de voortgang van de lopende ontwikkeling als in de verwachting van de maatregelen om deze te veranderen.

In die zin is de boekhouding waarlijk continuele registratie.

Ik kan echter van dit standpunt uit niet de gedachtensprong maken, die v.K. van ons vraagt, n.l. om in de jaarrekening geen winstbepalende rekening maar een vermogensbewakende balans te zien. De ondernemingsleiding zou de jaarrekening voor ,haar eigen belangen" niet nodig hebben? Misschien dan niet als we eigen belangen vervangen door interne doeleinden, ofschoon ook dan de stelling dubieus blijft, maar zeker wel voor die eigen doeleinden, die samenhangen met de vermogensverwerving. En ook dat zijn ,,eigen belangen".

De onderneming leeft niet bij de gratie van zich zelf alleen, maar is gebonden aan en wordt mede gevoed door de vermogensmarkt, waaruit vermogen naar de onderneming toevloeit, dan wel van waaruit van afvloeiing van vermogen uit de onderneming naar de buitenwereld wordt afgezien. Ook in deze relatie moet de communicatie zich op een kortere termijn dan het jaar afspelen. De kwartaalberichten van grote ondernemingen vervullen in dit opzicht een bijzonder nuttige, reeds onmisbaar geworden functie. Zij brengen de resultaten over het kwartaal, niet het vermogensbestand per het einde daarvan. Ook hieruit blijkt weer, hoe zeer in de berichtgeving het resultaat en niet de vermogensstand primair is. Ook wil ik uitdrukkelijk stellen, dat naast de berichtgeving op korte termijn die op jaartermijn haar eigen plaats en functie heeft, zoals ik elders al eens heb aangegeven en waarop ik nu niet behoef terug te komen. In de omstandigheid, dat de leiding reeds vóór de afloop van het jaar op de hoogte is van de nodige gegevens, zie ik dus geen argument voor verschuiving van de functie van de jaarrekening naar die van vermogensbepaling. Nog altoos vloeien deze beide functies voor mij tezamen. 
Met de aanduiding van het verband met de vermogensmarkt kom ik tot een sprekend bezwaar tegen v.K.'s uitspraak, dat winstuitkering een inleiding is tot de liquidatie van het ondernemingsvermogen. $\mathrm{Ze}$ is het tegendeel. De onderneming bestaat bij de gratie van de winstuitkering. Zonder winstuitkering kan de onderneming zich nog voortslepen, maar is een dynamische financiering uitgesloten.

De Lange heeft dit in zijn ,Dynamische Financiering” fraai ontwikkeld: de dividendpolitiek moet zodanig zijn, dat de toegang tot de vermogensmarkt wordt opgehouden. De continuiteit wordt gediend door een rationele dividend- en reserveringspolitiek, berustend op een op vervangingswaardecalculatie gebaseerde winstbepaling en niet door een uitsluitend op zich zelf gerichte vermogensbewaking. De onderneming moet uitkeerbare winst zo duurzaam mogelijk behalen; instandhouding van de kringloop is daarin middel om die duurzaamheid te bewerkstelligen. In deze visie, nogmaals, is de winstbepalende functie primair in het samenstel, dat de jaarrekening vormt.

$\mathrm{Er}$ is meer. V.K. zegt, dat wij met de balans de aandacht niet moeten richten op datgene dat wordt uitgekeerd, doch op het vermogensdeel dat voor de onderneming behouden blijft. De fuctie van de balans is bij hem een vermogensbewakende fuctie.

Ik vraag mij af, of dit gehele beeld van v.K. niet bedriegelijk is. V.K. ziet in het spiegelbeeld iets anders, voor wat in wezen hetzelfde verschijnsel is. Bepaling van de winst, onder vaststelling van wat de onderneming uit kan enerzijds en van wat behouden moet worden anderzijds, zou inleiding tot liquidatie zijn, maar vaststelling van het te behouden vermogen en van het deel dat op die grond de onderneming kan uitstromen - een identiek procédé - zou integendeel continuiteitshandhaving zijn?

Ik meen, dat v.K. het in dit opzicht willekeurige onderscheid tussen uit te keren deel en te behouden deel moet laten vallen. Hij zou moeten willen zien dat het gaat om de vaststelling van de totale vermogensaanwas, om daarbinnen te onderscheiden tussen wat uitkering en behoud moet of kan zijn. Het gaat om twee componenten van één geheel. In Van Muiswinkels „Schoonheidsfouten", waarnaar door v.K. met instemming wordt verwezen, komt dit facet goed tot uitdrukking.

Van Muiswinkel houdt de beide bestanddelen namelijk lange tijd tezamen. Hij vindt door vergelijking van het vermogen aan het begin en aan het einde van de periode het geldresultaat van die periode. Die totale vermogensaanwas pen de eventueel gedurende de periode reeds gedane uitkeringen) kan dan niet in z'n geheel worden uitgekeerd. De vermogensaanwas moet worden geanalyseerd, waarbij bepaald moet worden welk deel binnen de onderneming gebonden moet blijven (zoals het gunstige verschil tussen historische uitgaafprijs van de verbruikte produktiemiddelen en de actuele waarden van de nog aanwezige voorraden, alsmede de compensatie van de nadelen van uitgestelde vervanging van ondeelbare en ook deelbare voorraden) en een deel dat, afhankelijk van het beleid, uit te keren of in te houden is. Aldus zien wij bij v.M. een duidelijk beeld van de integratie in de vaststelling der samenstellende delen. Dat het operationeel funest zou zijn om in de praktijk volgens dit gedachtebeeld te werk te gaan of ook de vraag of de conceptie 
van Van Muiswinkel als zodanig wel aanvaardbaar is, zijn andere zaken, die nu niet terzake doen.

In de grenzen van de winstuitkering ligt besloten, dat ook zij de continuiteit dient en niet de liquidatie. Uitkering en behoud zijn twee facetten van een en hetzelfde vraagstuk, waartussen de grens op een en dezelfde grondslag moet worden getrokken. Ik kies dus, in tegenstelling tot v.K., niet voor de monistische balans, om begrippen te gebruiken waarmede Schmalenbach de bedrijfseconomie op een dwaalspoor dreigde te leiden, maar voor de dualistische.

1I Het lijkt, alsof v.K. in zijn tweede hoofdstuk zijn criterium van de continuiteitshandhaving zal gaan aangeven. V.K. introduceert het begrip „beklemd vermogen", het vermogen dat nodig is voor de continuiteitshandhaving. V. K. verwijt de vervangingswaardeleer, dat deze wel de winst definieert, doch niet beklemd vermogen ,,waarvoor men zelfs geen benaming heeft". Nu lijkt mij, dat beklemd vermogen in een vrij nauwe relatie moet staan tot het vermogen, dat volgens Van der Schroeff onder de klem der vervangingsverplichting ligt. Daarmede ontgaat de vervangingswaardetheorie dan zowel v.K.'s verwijt van gebrek aan terminologie als aan definitie. Maar wat is beklemd vermogen dan volgens v.K.?

Naar v.K.'s mening is er slechts één definitie mogelijk en wel die als het vermogen bij de aanvang van de verslagperiode (het eindvermogen dat de voorgaande balans toonde na aftrek van winstuitkeringen en bijtelling van vermogensstortingen).

Deze uitspraak is bij eerste lezing ongetwijfeld verbazingwekkend, omdat men eerder nog aan het eindvermogen zou denken of liever nog aan de vergelijking tussen begin- en eindvermogen, op dezelfde grondslag berekend. Trouwens, de definitie geeft alleen een tijdsbepaling, zegt verder niets en geeft dus ook geen kwantitatieve inhoud, wat zij volgens v.K.'s uitdrukkelijke aankondiging zou doen.

V.K. komt tot zijn uitspraak, omdat men naar zijn mening de winst niet door de resultatenrekening kan laten vaststellen. Daarmede overtrekt men haar mogelijkheden. De resultatenrekening kan de functie niet vervullen. Ten bewijze wijst v.K. op de theorie van de inhaalafschrijving. Daardoor kan de resultatenrekening niet normatief te werk gaan. De balans bevat daarentegen wel een normatief element, waaraan men de winst kan meten, aldus v.K., n.l. in de vorm van het vermogen bij het begin van de verslagperiode.

Ik voor mij kan in het beginvermogen niet meer zien dan een eenmalige feitelijke toestand, naar het inzicht van toen weergegeven. $\mathrm{Na}$ een jaar heeft het zijn betekenis verloren, dan is er immers weer een nieuw beginvermogen, n.l. van de opvolgende periode. Hoe kunnen deze momentsituaties meer normatief zijn dan de resultaten/vermogensaanwasrekening? Als de resultatenrekening ,reële risico's" inhoudt omdat ze de volledigheid van de inhaalafschrijvingen niet kan selecteren, dan geldt ditzelfde manco toch onverminderd of liever in veel sterkere mate voor de telkens op te maken (begin) balans? In mijn ogen zijn resultatenrekening,en balans weer tezamen één, ze 
zijn tezamen de jaarrekening, en wij brengen geen volledigheid aan of ontgaan niet het vraagstuk der inhaalafschrijvingen door de beginbalans als maatstaf boven de resultatenrekening te verkiezen.

Trouwens, v.K. gaat, n.m.m. geheel onverwacht, op een ander motief over. In de moderne winstleer, zegt hij, heeft men het normatieve element in de balans verspeeld, door de balans principieel op te maken in de valuta van het ogenblik, die een andere waarde heeft dan die welke op de voorgaande balans werd toegepast. Slechts, aldus v.K., met behulp van opeenvolgende balansen die het reële vermogen op onderling vergelijkbare wijze tonen, is men in staat het probleem op te lossen.

Twee opmerkingen passen hierbij: -

- v.K. heeft enige bladzijden tevoren er opgewezen dat reëel vermogen voor de aandeelhouder iets anders betekent dan voor de onderneming, n.l. instandhouding van de koopkracht van het aandeel;

de onderneming heeft volgens v.K. in tegenstelling tot de aandeelhouder alleen te maken met het prijsverloop van haar eigen produktiemiddelen. Het gezichtspunt van de aandeelhouder regardeert de balanstheoreticus niet.

Kritiek: de introductie van de ,valuta van het ogenblik" in de balans gaat juist in de richting van de aandeelhoudersproblematiek, corrigeert in algemene zin de koopkracht van het aandeel, maar juist niet het specifieke prijsverloop van de eigen produktiemiddelen van de onderneming.

III In zijn vierde hoofdstuk geeft v.K. een historisch overzicht van de onderscheidene balanstheorieën, hun ontstaan, bestaan en modulaties in de loop der tijden. Hierin geeft v.K. blijk van een grote kennis van en van interessant inzicht in de diverse theorieën en hun werking. Des te meer moet het bevreemden, dat hij geen onderscheid makt tussen de organische Bilanztheorie en de vervangingswaardetheorie, maar eenvoudig de laatste onder het etiketje van de eerste opvoert. Gezien de kennis van de schrijver moet dit welbewust zijn geschied. Nu kan ik niet aannemen dat de fraaie vergelijkende studie, die Abr. Mey over de theorieën van Limperg en Schmidt in de vroegere jaargangen, van dit tijdschrift heeft geplaatst, voor v.K. een onderontwikkeld gebied zou vormen. Dat v.K. daaraan zonder meer voorbij gaat, acht ik niet houdbaar. Er zijn daarvoor te grote verschillen tussen de opportune Tageswertbilanz van Schmidt en de theorie van de vervangingswaarde van Limperg.

Evenals bij de andere grepen uit de historie van de balansleer laat v. K. ook bij de bespreking van de theorie der vervanginswaarde de gelegenheid niet voorbij gaan om enige kritiek uit te oefenen. Zijn kritiek op de vervangingswaardetheorie kan in drie punten worden weergegeven.

a. De toepassing van het systeem vraagt bij voortduring een grote hoeveelheid arbeid, die bij doorgaande stijging van de prijs van de mankracht nauwelijks meer kan worden opgebracht. Slechts met computerhulp lijkt de uitvoering nog mogelijk .....(v.K.)

Ja, hier zijn we dan beland bij een heel lang bestaand en veel verteld 
sprookje. Natuurlijk betekent vervangingswaardetoepassing dat men zich rekenschap moet geven van nieuwe waarden in het bedrijf en dat men die ook in de administratieve verantwoording tot uitdrukking moet brengen. Maar men moèt dit doen, bij wijze van spreken op straffe van ondergang. De kosten zijn daarbij niet hoger dan wanneer geworsteld wordt met de oudste prijs of met de laagste prijs of nog erger met een gemiddelde prijs. De voorstelling van v.K. is ook in strijd met de feiten, waar goede voorbeelden van toepassing van de vervangingswaarde in de praktijk reeds lang bekend zijn, zonder dat enig bezwaar uit hoofde van de daaraan verbonden kosten wordt ondervonden. Eigenlijk acht ik v.K. een te goed vakman om nog met dit bezwaar voor de dag te komen.

b. De balansleer (winstleer) van de vervangingswaardeleer is gebonden aan een boekhoudkundig systeem ... De vervangingswaardeleer heeft een technisch systeem als normatief voorgedragen....... heeft zich met dit systeem geidentificeerd... keurslijf... uit de alternatieve mogelijkheden bleef slechts een techniek over. (v.K.)

Wel, dit is natuurlijk niet zo. Gelukkig is het niet gebleven bij het uitbrengen van de theorie, maar hebben aanhangers van de vervangingswaardetheorie ook methoden aangegeven waarlangs de theorie in de praktijk zou kunnen worden verwezenlijkt - nadat door kritisch gezinde lieden was beweerd dat de beginselen toch nooit in de praktijk zouden kunnen worden toegepast, enz. Daarbij heeft de z.g. continuele waarderegistratie (boekhouding in vervangingswaarde) veel instemming gevonden, maar dat betekent niet dat de theorie aan die techniek verkocht is, noch dat dit algemeen beginsel een keurslijf zou kunnen zijn. Wie met de materie uit de praktijk bekend is, weet hoeveel varianten er in de toepassing zijn en welke interessante problematiek er telkens nog weer blijkt te zijn. Ik verwijs voor de kanten die aan dit vraagstuk zitten overigens naar Starreveld's Leer van de Administratieve Organisatie.

c. De vervangingswaardetheorie redeneert niet verder dan de verkooptransactie, maar besteedt geen aandacht aan de wederinkooptransactie. (v.K.)

Dit ware inderdaad ,merkwaardig" om de terminologie van v.K. te gebruiken, voor een theorie, die zich op de vervanging, dus op de wederinkoop, richt.

Zie ik het bezwaar van v.K. goed, dan onderscheidt hij tweeërlei:

- de inkoop kan incidenteel of speculatief zijn. Ik ben van mening, dat de vervangingswaardetheorie zich uitdrukkelijk over de gevolgen van een dergelijke inkoop heeft uitgesproken.

- bij transacties in de continuiteit wordt geen rekening gehouden met de invloed op de winst van de inkooptransactie indien de wederinkoopprijs (b.v. wegens tijdsverschil) zou afwijken van de vervangingswaarde bij de verkoop. Ik meen dat ook dit aspect in de loop van de tijd door vervangingswaarde-theoretici is bezien. Ik verwijs naar de bijdrage van $\mathrm{J}$. de Jong in het Limperg-nummer van dit tijdschrift en noem ook Abr. Mey's waardeverantwoording en waardemoment, over welke publicatie indertijd in de kolommen van dit maandblad uitvoerig tussen Abr. Mey en v.K. is gepolemiseerd. 
IV Evenals v.K. bereiken wij nu het slot van onze beschouwingen. Ik ga voorbij aan enige bijkomende opmerkingen van v.K. - ofschoon het een tantaluskwelling is om in het bijzonder de beschuldiging aan het adres van de C.A.B. onaangeroerd te laten - en stuur rechtstreeks aan op de alinea, waarin hij zegt de vraag te gaan behandelen, hoe een balans kan worden verbeterd. V.K. voert op dit moment een onderscheid in tussen de vermogensbeschermende functie van de balans en de informatieve functie en gaat dan voor elke functie afzonderlijk na, op welke wijze deze „,tot bevrediging” kan worden vervuld.

Nu wil ik aanstonds de mening uitspreken, dat het onderscheid tussen beschermende en informatieve functie van de balans $\mathrm{m}$.i. ten onrechte wordt gemaakt. De jaarrekening heeft ten doel, een getrouw beeld te geven van grootte en samenstelling van vermogen en kapitaal per het einde van het jaar en van de resultaten over dat jaar. Daarin liggen alle functies besloten, van juiste weergave van vermogen tot resultatenbepaling en daarmede van goede informatie van alle betrokkenen. De elementen van die informaties kunnen niet worden ontleend of van elkaar worden gescheiden, op straffe van inbreuk op hun beider juistheid. Zo ergens van integratie sprake moet zijn, dan is het hier. V. K. wil echter scheiden. Zelfs is volgens hem geen andere volgorde van behandeling mogelijk dan eerst de vermogensbeschermende functie te bezien. Het meest in de praktijk verbreide Niederstwertprinzip is ondeugdelijk, zegt hij, omdat het vermogen te laag en de winst - bij stijgend prijsniveau - te hoog wordt voorgesteld. Vervangingswaardeleer of lifo/nifosysteem kunnen, aldus $v . K$., niet ter verbetering worden toegepast, want dan zou men de administratie gedeeltelijk moeten herschrijven (vrage: zouden we die dringende verbetering dan maar niet aanbrengen door de administratie van meet af aan daarop in te stellen? !). En dan tovert v. K. vrij onverwacht, het konijn uit de hoed. Zijn aanbeveling luidt: voor de winstbepaling het ijzeren-voorraad-systeem toe te passen en mogelijk ook de afschrijving op basis van het huidige prijsniveau te corrigeren. Daarmede is v. K. er nog niet, want zoals hijzelf aangeeft, is men dan verder verwijderd geraakt van de informatieve functie, daar het vermogen nog kleiner wordt voorgesteld. Dus zegt v. K.: breng het vermogen op de vereiste hoogte en breng de toegepaste verhoging naar de creditzijde van de balans.

$\mathrm{Ja}$, met hybridische varianten kan men soms verrassende resultaten bereiken, die er op het eerste gezicht niet onaantrekkelijk uitzien. Zo ook hier, want tenslotte komt v.K. - m.i. via een aantal kunstgrepen waarin men een algemene theorie of grondslag van waarde- en winstbepaling maar al te zeer mist tot een niet onaardige toepassing van de vervangingswaarde. Om dit laatste punt te motiveren, mag ik in herinnering brengen, dat N.J. Polak in zijn "Goed koopmansgebruik" zoekt naar een fiscaal aanvaardbare basis voor toepassing van de vervangingswaarde, dat hij daarvoor het vervangingskoopstelsel ontwikkelde, en dat de voorbeelden die Polak's methode illustreren zonder uitzondering aan het ijzeren-voorraad-stelsel zijn ontleend!

Maar nu ga ik terug naar v.K.'s eerder uitgesproken stelling, dat de 
ondernemingsleiding in de loop van het jaar reeds alles weet van wat de jaarrekening kan verschaffen. Wat weet echter die ondernemingsleiding bij toepassing van de ideeën van V.K.? In de loop van het jaar heeft de onderneming dan voor het grondstoffenverbruik de inkoopprijzen en zijn de afschrijvingen op duurzame aktiva op historische waarden gebaseerd. De omrekening tot ijzeren-voorraad- prijzen verschaft bij een groot assortiment van voorraden aan het jaareinde handen vol werk, de overige herwaarderingen aan het jaareinde komen op een ongelegen moment. Tenslotte zij opgemerkt, dat de herwaarderingsreserve van v.K. in een ,,wisselende maat" is uitgedrukt.

Het moderne beginsel van administratie en controle, de gedynamiseerde verantwoording, onmisbaar ook voor de resultaten- en vermogensbepaling op korte termijn, is bij dat systeem van eenmalige jaarlijkse herziening niet toepasbaar. De ondernemingsleiding moet bij voortduring en ten behoeve van elke beslissing de juiste en momentele waarden van de aktiva als ook de resultaten op ruiltransactiebasis kennen .... wie zei ook weer iets tegen continuele registratie in vervangingswaarde?

Let wel, de situaties in het bedrijfsleven zijn oneindig gevariëerd en niet altijd zal er de behoefte zijn, terecht of ten onrechte, de genoemde eisen alle vervuld te zien. Zowel heel eenvoudige als zeer gecompliceerde situaties kunnen de vraag naar een vereenvoudigde toepassing der vervangingswaardegedachte oproepen. Toevallig kreeg ik juist dezer dagen een onderhandse notitie van enige jonge collega's in handen, die oprecht naar een goede praktische uitvoerbaarheid van de vervangingswaardetheorie zochten. Met hun instemming kan ik daarvan hier iets vertellen. $\mathrm{Zij}$ komen tot een resultaat, dat de methode van v.K. dicht benadert. Kort samengevat komt hun voorstel t.a.v. vlottende voorraden hierop neer:

Bepaal de normale (=ijzeren) voorraad

- Bepaal de waarde van de voorraad volgens het ijzeren-voorraad-stelsel en de daarmee samenhangende brutowinst op goederen

Bepaal de waarde van de voorraad tegen (benaderde) vervangingswaarde en breng het verschil met de in het vorig lid berekende waarde, onder aftrek van latente belastingen, naar het ijzeren-voorraad-fonds.

Ook hier dus het idee van winstbepaling op basis van de vervangende aankopen, aangevuld met balanscorrectie terwille van de voorstelling van de grootte van het vermogen.

Aldus bereikt men wel het een en ander en onder omstandigheden kan iets beter zijn dan niets. Ik zie echter, naast de reeds genoemde bezwaren, het gevaar van uitholling van de vervangingswaardegedachte door middel van een rekentruc. De vervangingswaardetheorie bevat nog wel het een en ander meer dan hier ,gecorrigeerd" wordt. Daarbij is de theorie een kwantitatieve theorie, waaraan voor een alpha-theorie een grote mate van exactheid eigen is. Wil ze betekenis hebben voor de praktijk, dan moet die exactheid enerzijds operationeel zijn, anderzijds door benaderde methodieken niet al te zeer worden aangetast. De bedoelde collega's zien in hun voorstel de meest effectieve amendering op de vervangingswaardetheorie. Kijk, we kunnen de theorie niet door een rekenmethodiek amenderen, wel kunnen we trachten 
een bruikbare variant in de toepassing te vinden. Als zodanig wil ik het onderzoek van deze collega's gaarne toetsen en aanmoedigen, maar ik denk niet dat collega v.K. bereid is zijn balanswaardering in dat licht te (doen) beschouwen. 